\title{
ANÁLISE E CORRELAÇÃO DE CITOCINAS INFLAMATÓRIAS NO LÚPUS ERITEMATOSO SISTÊMICO
}

\author{
ANALYSIS AND CORRELATION OF INFLAMMATORY CYTOKINES IN SYSTEMIC \\ ERITEMATOSUS LUPUS
}

\author{
REIS, Camila Carneiro dos ${ }^{1}$; PEREIRA, Sâmia Emanuely da Silva ${ }^{1}$; DE \\ SOUZA, Luan Kelves Miranda ${ }^{1^{*}}$. \\ ${ }^{1}$ Faculdade de Ciências Humanas, Exatas e da Saúde do Piauí/Instituto de Educação Superior \\ do Vale do Parnaíba - FAHESP/IESVAP \\ *luankelves11@gmail.com
}

\section{RESUMO}

O Lúpus Eritematoso Sistêmico (LES) é uma doença inflamatória crônica, multissistêmica, de natureza autoimune, caracterizada pela produção de diversos autoanticorpos. Analisar o grau de atividade das citocinas TNF-a, IL6, IL10 e IL17 nos pacientes com LES, e associar seus níveis com as manifestações clínicas-laboratoriais e sua relação com o prognóstico. O levantamento bibliográfico dos artigos foi realizado a partir da consulta na BIREME na SCIELO PUBMED, publicados entre 2005 a 2019. Foi realizada uma busca no formulário avançado dos termos lúpus eritematoso sistêmico, citocinas, doenças autoimunes e inflamação, bem como os seus termos em inglês. Após leitura do título e resumo, foram selecionados 79 artigos para leitura na integra. A partir da pesquisa, constatou-se que as citocinas desempenham um papel importante na patogênese do LES. Pois, foi visto que a IL-4 atua na inflamação; e a IL-6 está envolvida na produção de auto-anticorpos em pacientes com LES, e considerada também importante biomarcador de lúpus nefrítico (LN), juntamente com o TNF- $\alpha$. Além dessas, a IL-10 que mesmo sendo considerada uma citocina anti-inflamatória, está superexpressada em pacientes com lúpus. Por fim, a IL-17 também foi considerada importante na patogênese do LES. Os dados acerca das possíveis associações entre as citocinas citadas e o LES são evidentes, mostrando que alterações nesses componentes podem levar a maior atividade da doença.

Palavras-chave: Lúpus Eritematoso Sistêmico; Citocinas; Doenças Autoimunes; Inflamação. 
REIS, Camila Carneiro dos; PEREIRA, Sâmia Emanuely da Silva; DE SOUZA, Luan Kelves Miranda.

\section{INTRODUÇÃO}

O Lúpus Eritematoso Sistêmico (LES) é uma doença inflamatória crônica, multissistêmica, de natureza autoimune, caracterizada pela produção de diversos autoanticorpos, formação e deposição de imunocomplexos, levando a dano tecidual. Possui grande variação etiopatogênica, com participação de fatores hormonais, ambientais, imunológicos e genéticos ${ }^{1}$.

Além disso, uma variedade de citocinas tem sido associada ao LES. Como a Interleucina-10 (IL-10), que é um potente estimulador das células B e um inibidor da função das Células Apresentadoras de Antígenos (APCs) e das células $T^{2}$. E junto com a Interleucina-6 (IL-6) tem grande influência na produção de autoanticorpos no LES. O Fator de Necrose Tumoral alfa (TNF- $\alpha$ ), que apesar de controvérsias a sua relação com o LES, ele tem sido alvo terapêutico eficaz no tratamento do LES, através da sua inibição ${ }^{3}$.

Existe ainda, estudos recentes que mostram que níveis séricos de Interlecuina-17 (IL-17) estão aumentados no LES. (4,5,6,7). No entanto, não foram associados com atividade da doença e sintomas relacionados. Logo, são necessários estudos para determinar se a dosagem de IL-17 pode ser utilizada como um biomarcador em LES. Bem como, se tornar um novo alvo farmacológico para a doença em questão.

Partindo do que é observado na literatura, e levando em consideração as avaliações já elucidados sobre as citocinas envolvidas no LES, a presente revisão reúne os dados coletados em outros artigos com intuito de: saber se as citocinas TNF- a, IL6, IL10 e IL17 são as mais prevalentes nos pacientes com LES e confirmar se as citocinas TNF- $\alpha$, IL6, IL10 e IL17 são responsáveis por maior parte do quadro sintomatológico no paciente com LES.

Analisar sobre as citocinas inflamatórias com LES poderá trazer possíveis explicações sobre a patologia assim como correlacioná-las entre si. Dessa forma, poderá mencionar o papel que cada uma desempenha no desenvolvimento do LES e mais estudos a fim de saber sobre sua importância na patologia estudada. 
REIS, Camila Carneiro dos; PEREIRA, Sâmia Emanuely da Silva; DE SOUZA, Luan Kelves Miranda.

\section{METODOLOGIA}

Para a concretização deste estudo, buscou-se publicações sobre a temática utilizando os bancos de dados da saúde como Literatura LatinoAmericana e do Caribe em Ciências da Saúde (LILACS), biblioteca virtual Scientific Eletronic Library Online (SCIELO) e o banco de dados da Biblioteca Nacional de Medicina dos Estados Unidos (PUBMED). Os critérios de inclusão corresponderam a artigos indexados no período de publicação compreendido entre os anos de 2005 a 2019. Alguns artigos foram adicionados fora desses anos compreendidos, devido à importância para esta revisão.

Foi realizada uma busca no formulário avançado os termos lúpus eritematoso sistêmico, citocina, doenças autoimunes e inflamação, bem como os seus termos em inglês, systemic lupus erythematosus, cytokines, autoimune disease e inflammation. As palavras-chaves utilizadas para o levantamento dos dados foram escolhidas de acordo com os Descritores em Ciências da Saúde (DECS), por ser um vocabulário controlado que tem por finalidade permitir o uso de terminologia comum para indexação e recuperação de artigos científicos nas bases de dados, proporcionando um meio que classifica as informações e facilita as pesquisas bibliográficas (DECS).

Após a seleção dos artigos nas bases de dados, foi realizada uma análise exploratória deles, em que foram excluídos os artigos de reflexão, artigos de opinião, artigos repetidos, resenhas, anais de congresso, editoriais e artigos que não abordaram diretamente o tema deste estudo. Em seguida, foram analisados os respectivos abstracts, em que foram selecionados os artigos que discorriam sobre com a etiologia, principais citocinas envolvidas, tratamento e prognóstico no LES pelos pesquisadores nas diferentes bases de dados.

Essas informações foram organizadas em tabela, unindo os resultados de todas as bases de dados pesquisadas, utilizando a Microsoft Excel. Além disso, os artigos foram organizados por ano de publicação para melhor visualização da abordagem do assunto lúpus eritematosos sistêmicos e sua relação com citocinas ao longo do tempo, pelos pesquisadores que publicam artigos em periódicos que estão indexados nestas bases de dados (Tabela 01). 
REIS, Camila Carneiro dos; PEREIRA, Sâmia Emanuely da Silva; DE SOUZA, Luan Kelves Miranda.

1

2

3

4

5

6

7

8

9

\section{RESULTADOS}

A patogenicidade do LES está ligada a predisposição genética e vários fatores os quais sinalizam de forma exacerbada para as células $T$ e $B$. Anormalidades em citocinas estão envolvidas nessa patogênese e servem também como marcadores revelando desregulação no sistema imunológico. Como a IL-10 que é estimuladora das células T e APCs. Outras citocinas próinflamatórias também estão ligadas às manifestações da LES, como o IL-6, IL17 e TNF- $\alpha$, sendo cada uma responsável pelo desencadeamento de alguma manifestação da doença ${ }^{8,9}$ (Tabela 02).

O sistema imunológico fornece proteção aos tecidos danificados por microrganismos infecciosos ou danos físicos. Na autoimunidade o sistema imunológico reconhece e ataca seus próprios tecidos, ou seja, a autodestruição. Acredita-se que vários agentes, como fatores genéticos e gatilhos ambientais, desempenhem um papel importante no desenvolvimento de doenças autoimunes. Uma característica comum de todas as doenças autoimunes é a presença de auto-anticorpos e inflamação, incluindo fagócitos mononucleares, linfócitos $T$ autorreativos e células $B$ produtoras de autoanticorpos. Há muito se sabe que as células B produzem autoanticorpos e, assim, contribuem para a patogênese de muitas doenças auto-imunes. No LES, a resposta autoimune é dirigida contra antígenos difundidos, e é caracterizado por anticorpos circulantes e deposição de imunocomplexos que podem desencadear um dano inflamatório nos órgãos ${ }^{10}$.

Recentemente, foi descoberto o papel da interleucina-4 (IL-4), que pode participar do mecanismo do reumatismo, tendo papel fundamental na inflamação. Foi relatado também que a IL-4 participa na regulação da ativação, diferenciação, proliferação e sobrevivência de diferentes tipos de células T. A IL4 é uma citocina multifuncional que amplifica ou inibe as funções gerais das células $B$ no lúpus, mas poucos relatos sugerem que a IL-4 tenha um papel supressor de células $T$ no lúpus ${ }^{49}$. Além disso, essa citocina tem um efeito imunomodulador nas células $B$, mastócitos, macrófagos e muitos tipos de células ${ }^{11}$.

De certo, a IL-4 pode inibir a produção de citocinas pró-inflamatórias, como TNF- $\alpha$, IL-1, IL-6 e prostaglandina E2 (PGE2). Além disso, a IL-4 também 
REIS, Camila Carneiro dos; PEREIRA, Sâmia Emanuely da Silva; DE SOUZA, Luan Kelves Miranda.

1 pode regular positivamente a expressão de mediadores anti-inflamatórios, como

2 os antagonistas dos receptores da IL-1 e os receptores da IL-1 tipo II $^{12,13}$.

3 Linfócitos $\mathrm{T}$, basófilos e mastócitos $\mathrm{T}$ ativados podem secretar IL-4, que regula a proliferação de células $B$ e macrófagos, e modula a função imunológica específica de células hematopoiéticas ${ }^{14}$. Além disso, IL-4 desempenha um papel vital na regulação da diferenciação de células $T$ imaturas estimuladas por antigêno e desenvolve-se em células Th2 produzidas por IL-4 por sinalização mediada por receptor de Interleucina-4 (IL-4R) ${ }^{15}$.

No entanto, a transdução da via de sinalização de IL-4 também é encontrada para desempenhar um mecanismo pró-inflamatório do mecanismo molecular ${ }^{11}$. A função da IL-4 ainda é controversa no LES, em algumas pesquisas, o resultado dos perfis de citocinas mostra que o LES é acompanhado não teve diferença óbvia em comparação com controles saudáveis ${ }^{18,19}$.

Outra citocina relaciona é a IL-6, que segundo estudos, está envolvida na produção de auto-anticorpos em pacientes com LES ${ }^{20}$. Sobre a IL-6 pode ser citado a grande capacidade de produzir anticorpos, também foi detectada também como um importante biomarcador de Lúpus Nefrítico (LN), juntamente com outras citocinas, pois esteve aumentada em análises de excreção o que reflete o grau de inflamação em pacientes com o quadro de LN. A IL-6 juntamente com a IL-10 mostrou-se elevada também em estudos com pacientes em tratamento padrão $0^{3,8,9}$.

A cascata de coagulação e o sistema complemento podem interagir indiretamente através da regulação de mediadores inflamatórios ${ }^{21,22}$. A interação entre C5a e citocinas inflamatórias foi visto, incluindo um efeito sobre a produção do Fator de Necrose Tumoral Alfa (TNF-a) e Interleucina 6 (IL-6) ${ }^{23}$. Então, essas citocinas podem aumentar a ativação da cascata da coagulação promovendo a expressão de coagulantes e inibindo a produção de anticoagulantes ${ }^{24}$.

As interações entre o sistema complemento, a cascata de coagulação e a resposta inflamatória foram relatadas como estando associadas à gravidade do LES em vários cenários clínicos e experimentais ${ }^{21,25}$. No entanto, o papel potencial dessas interações para a gravidade da doença nos pacientes com LES ainda não foi determinado. 
REIS, Camila Carneiro dos; PEREIRA, Sâmia Emanuely da Silva; DE SOUZA, Luan Kelves Miranda.

Outra característica que o paciente com LES pode apresentar, é a remoção prejudicada de células apoptóticas, levando a um impacto negativo na homeostase tecidual, através da exposição do sistema imune a componentes intracelulares que são pró-inflamatórios e imunogênicos e contribui, assim, para o desenvolvimento de inflamac, ão crônica e doenças autoimunes ${ }^{26}$. Além disso, outra citocina relacionada é a Interleucina-10 (IL-10), que geralmente é considerada uma citocina anti-inflamatória e imunossupressora. No entanto, é superexpressada em pacientes com lúpus e, em alguns casos, relata-se que atua como uma molécula que promove o lupus ${ }^{27}$. Diversos estudos demonstraram que os níveis de IL-10 no soro/plasma estavam significativamente aumentados em pacientes com LES em comparac,ão com os controles ${ }^{8,28}$.

A IL-10 foi originalmente identificada por Mosmann e colaboradores ${ }^{29,30}$. Desde esta descrição original, a lista de células produtoras de IL-10 expandiuse rapidamente, assim como o número de células que são capazes de responder a esta citocina. As quatro principais fontes de células T de IL-10 são células $T$ helper tipo 2 (Th2), subconjuntos de células $T$ reguladoras designadas por células Tr1, Th1 e Th1731. As células T CD8 ${ }^{+}$também produzem IL-10. Outros produtores importantes de IL-10 incluem monócitos e macrófagos apropriadamente estimulados, bem como alguns subconjuntos de células dendríticas (DCs). As células B humanas também são uma fonte potencialmente importante de $\mathrm{IL}-10^{32}$, assim como alguns granulócitos, incluindo eosinófilos e mastócitos $^{33}$. Fontes celulares não imunes de IL-10 incluem queratinócitos, células epiteliais e até mesmo células tumorais ${ }^{34}$.

Níveis aumentados de IL-10 têm sido correlacionados à atividade da doença ou à produção de autoanticorpos que podem contribuir para a patogênese do LES e/ou modular a diferenciac,ão e a func,ão das células dendríticas ${ }^{28}$. As células dendríticas derivadas de monócitos ativados por soro de pacientes com LES, ou após a exposic,ão à IL-10 exógena, tinham níveis reduzidos de expressão de antígenos leucocitários humanos (HLA)-DR e apresentavam capacidade prejudicada de estimular a proliferação de linfócitos $T$ alogênicos ${ }^{35}$.

A IL-10 é uma citocina multifuncional secretada por uma variedade de células. Não só inibe a ativação do sistema de monócitos / macrófagos e a síntese de citocinas de monócitos e citocinas inflamatórias, mas também 
REIS, Camila Carneiro dos; PEREIRA, Sâmia Emanuely da Silva; DE SOUZA, Luan Kelves Miranda.

1 promove a proliferação e maturação de células $T$ não dependentes de

2 monócitos, estimulando a proliferação de células B específicas de antígeno.

3 Evidências crescentes indicam que a IL-10 desempenha um papel importante

4 tanto no surgimento como no desenvolvimento de doenças autoimunes, como

5 Lúpus Eritematoso Sistêmico (LES). No entanto, os mecanismos exatos da IL-

610 em doenças auto-imunes permanecem obscuros ${ }^{36}$.

A interleucina-10 (IL-10) é uma citocina do tipo II e o membro 'fundador'

8 de uma família de citocinas que inclui interleucina-19 (IL-19), interleucina-20 (IL-

9 20), interleucina-22 (IL-22), interleucina-24 (IL-24), interleucina-26 (IL-26), interleucina-28 (IL-28), e interleucina-29 (IL-29) ${ }^{37}$. Todas essas citocinas possuem organização genômica intron-exônica semelhante, ligam-se a receptores com estruturas semelhantes e, em alguns casos, compartilham componentes. Apesar desses pontos em comum, as citocinas nessa família têm pelas células que produzem a citocina, as células que respondem a elas e 0 ambiente imunológico no qual são liberadas.

Não há dúvida de que as células T-helper tipo 1 (Th1) e mais recentemente as células T-helper tipo 17 (Th17) são capazes de produzir IL-10, e estas células representam uma importante fonte de IL-10 durante doenças infecciosas ${ }^{38}$, mas parece mais provável que esta produção possa ocorrer como mecanismo homeostático para prevenir a ativação descontrolada de células $T^{31}$. Esta produção de IL-10 em células Th1 e Th17 pode ocorrer através de um mecanismo de "força de estímulo", que também pode ser verdadeiro para as células $\mathrm{B}^{39}$.

Também foi demonstrado que TNF- $\alpha$ está relacionado a nefrite lúpica $(\mathrm{NL})$, o qual é também considerado um potencial biomarcador específico para lesão dos tecidos ${ }^{9}$. São amplamente utilizados bloqueadores de Fator de Necrose Tumoral alfa (anti-TNF) como terapia em doenças imunomediadas e reumáticas ${ }^{40}$.

A família de citocinas da interleucina 17 (IL-17) está envolvida em várias doenças inflamatórias crônicas. Apesar dos achados contraditórios e da falta de causalidade em estudos clínicos, a inibição da IL-17 para o LES recuperou a atenção como uma via terapêutica potencial, após demonstrar capacidade modificadora da doença na espondilite anquilosante. Os pacientes com LES 
REIS, Camila Carneiro dos; PEREIRA, Sâmia Emanuely da Silva; DE SOUZA, Luan Kelves Miranda.

1 apresentaram maiores níveis de lgG, menores contagens de células T e B, mas

2 os níveis medianos de IL-17A não diferiram dos controles $(28,4$ vs. $28,4 \mathrm{pg} / \mathrm{mL}$,

$3 p=0,9$ ). Em pacientes com LES, a IL-17A não se correlacionou com SLEDAI-2K

4 (Systemic Lupus Erythematosus Disease Activity Index) ou SDI, mas foi

5 inversamente relacionada com a idade (coeficientes de correlação, Rs. = - 0,29,

$6 p<0,05$ ), pressão arterial sistólica (Rs. $=-0,31, p<0,05$ ), anos de tabagismo

7 (Rs. $=-0,43, p<0,05)$, coração acumulado (Rs. $=-0,22, p<0,05)$ e dano à

8 malignidade (Rs. $=-0,18, p<0,05)$. Correlações sorológicas para IL-17A foram encontradas com os níveis de imunoglobulina $G(\lg G)$ (Rs. $=0,21, p<0,05)$, proteína $C$ reativa de alta sensibilidade (PCR-us) ( $R s=0,28, p<0,05$ ), proteinúria $(R s .=0,64, p<0,05)$ e pré-albumina (Rs. $=-0,22, p<0,05)$. Dados longitudinais mostraram apenas flutuações modestas nos níveis de IL-17A, independente do SLEDAI-2K ${ }^{41}$.

\section{DISCUSSÃO}

O LES tem relação com quadros de estresse no organismo, considerando-a como uma afecção psicossomática ${ }^{42}$. Estudos mostram que as células do sistema imunológico sofrem influência dos sistemas nervoso e endócrino e o estresse age nestes sistemas ao gerar um aumento de secreção das substâncias conhecidas como catecolaminas (adrenalina e noradrenalina). As catecolaminas afetam as reações imunes de várias maneiras, inclusive, gerando a formação de anticorpos contra os constituintes do próprio organismo. Desse modo, situações de estresse estão relacionadas com à modulação do sistema imunológico, podendo, portanto, estar relacionada às doenças autoimunes, como no $\mathrm{LES}^{43}$.

Infecções virais, bacterianas, parasitárias e fúngicas são apontadas como fatores que predispõem pacientes aos LES, associados a genética e fatores ambientais. Isso se deve à relatos de que alguns vírus e bactérias tem a capacidade de produzir superantígenos que induzem a ativação dos linfócitos $T$ e B autorreativos, causando assim a síntese de citocinas e autoanticorpos. Um exemplo de citocina é o interferon alfa (IFN- $\alpha$ ), o qual contribui no desenvolvimento inflamatório e autoimune e é encontrado em altas concentrações em pacientes em períodos de surtos da doença ${ }^{44,45}$. 
REIS, Camila Carneiro dos; PEREIRA, Sâmia Emanuely da Silva; DE SOUZA, Luan Kelves Miranda.

Segundo estudos, a vitamina $\mathrm{D}$ tem importante papel no diagnóstico de doenças autoimunes, como LES. Em parte, esse papel é devido a desregulação na produção de citocinas o que pode causar uma deficiência da vitamina $D$, sendo a suplementação dessa vitamina, uma medida terapêutica, a fim de obter aumento dos níveis séricos da vitamina $D$ e assim melhorar de forma significativa os sintomas e complicações da doença ${ }^{46}$. Outra justificava para a suplementação de vitamina $D$ é o fato de que no tratamento da LES é recomendado a diminuição da exposição à luz solar, a qual é a sua principal fonte de produção 47,48 .

Como dito, as citocinas desempenham um papel na patogênese de várias doenças reumáticas, como lúpus eritematoso sistêmico. Recentemente, foi descoberto o papel da interleucina-4 (IL-4), que pode participar do mecanismo do reumatismo, tendo papel fundamental na inflamação. Foi relatado também que a IL-4 participa na regulação da ativação, diferenciação, proliferação e sobrevivência de diferentes tipos de células T. A IL-4 é uma citocina multifuncional que amplifica ou inibe as funções gerais das células B nos lúpus, mas poucos relatos sugerem que a IL-4 tenha um papel supressor de células $T$ nos lúpus ${ }^{49}$.

A função da IL-4 ainda é controversa no LES, em algumas pesquisas, o resultado dos perfis de citocinas mostra que o LES é acompanhado por menor produção de IL-4 ${ }^{16,17}$. Mostrando que a expressão de IL-4 no LES não teve diferença óbvia em comparação com controles saudáveis ${ }^{18,19}$.

Esses resultados ratificam a ideia de que a ação das citocinas é mais complexa do que a simples mensuração de seus valores no paciente com LES. Visto que, embora a níveis séricos insignificantes, a IL-4 desempenha um papel significativo no LES. A maioria dos estudos se concentrou nas propriedades estimuladoras de células B da IL-4 no desenvolvimento da produção de autoanticorpos. Embora o nível de IL-4 no LES ainda seja controverso, o papel da IL-4 desempenha um papel regulatório na imunidade humoral e imunidade celular ${ }^{11}$.

Outra citocina relaciona é a IL-6, que segundo estudos, está envolvida na produção de autoanticorpos em pacientes com LES ${ }^{20}$. Sobre a IL-6 pode ser citado a grande capacidade de produzir anticorpos, também foi detectada também como um importante biomarcador de Lúpus Nefrítico (LN), juntamente com outras citocinas, pois esteve aumentada em análises de excreção o que 
REIS, Camila Carneiro dos; PEREIRA, Sâmia Emanuely da Silva; DE SOUZA, Luan Kelves Miranda.

1 reflete o grau de inflamação em pacientes com o quadro de LN. A IL-6 juntamente com a IL-10 mostrou-se elevada também em estudos com pacientes em tratamento padrão $0^{3,8}$.

As interações entre o sistema complemento, a cascata de coagulação e a resposta inflamatória foram relatadas como estando associadas à gravidade do LES em vários cenários clínicos e experimentais ${ }^{21,25}$. No entanto, o papel potencial dessas interações para a gravidade da doença nos pacientes com LES ainda não foi determinado.

Em estudo recente, com pacientes em fase de remissão da doença - que apresentavam e que recebiam tratamento padrão, e controles sem a doença, as concentrações séricas de IL-6 e IL-10, apresentavam-se no grupo de pacientes em comparação com os controles. Além de redução na capacidade de fagocitose dos neutrófilos circulantes e redução da expressão de CD11b em linfócitos, o TNF- $\alpha$ não diferiu entre os dois grupos estudados ${ }^{8}$.

Dessa forma, esses pacientes apresentam maior risco de adquirir infecções bacterianas associadas a elevadas taxas de morbidade e mortalidade, devido as alterações na imunidade inata, mesmo em fase de tratamento e sem atividade da doença. Outra característica que o paciente com LES pode apresentar, é a remoção prejudicada de células apoptóticas, levando a um impacto negativo na homeostase tecidual, através da exposição do sistema imune a componentes intracelulares que são pró inflamatórios e imunogênicos e contribui, assim, para o desenvolvimento de inflamação crônica e doenças autoimunes ${ }^{26}$.

Todas essas citocinas possuem organização genômica intronexônica semelhante, ligam-se a receptores com estruturas semelhantes e, em alguns casos, compartilham componentes. Apesar desses pontos em comum, as citocinas nessa família têm atividades biológicas muito diferentes, que são em grande parte determinadas pelas células que produzem a citocina, as células que respondem a elas e o ambiente imunológico no qual são liberadas. Não há dúvida de que as células Th1 e mais recentemente as células Th17 são capazes de produzir IL-10, e estas células representam uma importante fonte de IL-10 durante doenças infecciosas ${ }^{38}$, mas parece mais provável que esta produção possa ocorrer como mecanismo homeostático para prevenir a ativação descontrolada de células $T^{31}$. 
REIS, Camila Carneiro dos; PEREIRA, Sâmia Emanuely da Silva; DE SOUZA, Luan Kelves Miranda.

Esta produção de IL-10 em células Th1 e Th17 pode ocorrer através de um mecanismo de "força de estímulo", que também pode ser verdadeiro para as células $\mathrm{B}^{39}$. Também foi demonstrado que TNF- a está relacionado a NL, o qual é também considerado um potencial biomarcador específico para lesão dos tecidos ${ }^{9}$. São amplamente utilizados bloqueadores de Fator de Necrose Tumoral alfa (anti-TNF) como terapia em doenças imunomediadas e reumáticas ${ }^{40}$.

Outro importante biomarcador para ser verificado é a $\mathrm{N}$-acetil- $\beta$ - $D$ glucosaminidase (NAG), a qual está aumentada em pacientes com quadro de nefrite provocada por LES. A NAG é um marcador de disfunção tubular. Pacientes com NL podem apresentar efeitos tóxicos manifestados com proteinúria e anticorpos antitubulares patogênicos da membrana basal que podem contribuir para a disfunção tubular. A NL é considerada a complicação mais grave de LES e é um importante caracterizador de prognóstico ruim.

A importante glicoproteína de Tamm-Horsfall (THP), atua no trato urinário como molécula de ligação entre microbianos patogênicos e diferentes quimiocinas ou citocinas. Normalmente, a quantidade de THP excretada na urina normal seria de aproximadamente 50 a $150 \mathrm{ml}$ por dia9 .

É também válido lembrar que a principal função do THP é impedir que microrganismos patogênicos fixem e penetrem no interstício urinário. É produzido somente pelas células epiteliais no ramo ascendente espesso na alça de Henle e nos túbulos contorcidos proximais e a diminuição ou alteração metabólica reflete dano renal por qualquer causa ${ }^{9}$.

Outros importantes contribuintes para a patogênese da NL são os anticorpos antidsDNA. Estes se ligam a antígenos ou materiais de cromatina desencadeando ativação e proliferação celular como também processos fribóticos e inflamatórios. Podem também desencadear ativação do complemento e formar complexos imunes ${ }^{50,51,52}$.

Várias patologias que estão associadas com o LES, algumas comuns e outras raras. Entre eles podem ser citadas a Glomerulonefrite Rapidamente Progressima (RPGN). Essa síndrome tem como característica perda abrupta da função renal. Entre os tipos, a Glomerulonefrite Crescênica Imune Pauci (PIGG) é a mais comum. É rara em associação com a LES, porém é uma das maiores causas de PIGG. Caracteriza-se por inflamação glomerular intensa com nenhum ou pouco depósito imunológico ${ }^{53}$. Outro exemplo de patologia associada ao LES 
REIS, Camila Carneiro dos; PEREIRA, Sâmia Emanuely da Silva; DE SOUZA, Luan Kelves Miranda.

1 e a causas secundárias é a Glomerulonefrite Membranoproliferativa (GNMP). É

2 consequente principalmente de infecção viral do Hepatite C (HCV), LES e Artrite

3 Reumatoide, também uma doença autoimune ${ }^{54}$.

O diagnóstico de LES inclui muitos sintomas e sinais inespecíficos. Devido a isso os o American College of Rheumatology (ACR) definiu critérios, clínicos e imunológicos, a fim de facilitar a hipótese diagnóstica. Entre eles é válido mencionar um sinal bem comum na LES como a lesão vascular da pele, a qual afeta a maioria dos pacientes em todo o trajeto da doença. É importante citar também a trombocitopenia $<100.000 / \mathrm{mm}^{3}$ e leucopenia $<4.000 / \mathrm{mm}^{3}$ pelo menos uma vez cada um, proteinúria urinária/creatinina - ou 24 horas de proteína urinária- representado $500 \mathrm{mg}$ de proteína por 24 horas, e outros $55,56,57$.

Por ser multissitêmica, o LES é um desafio ser diagnosticado ao aparecer lesões em órgãos alvos sem os critérios de sinais e sintomas juntos. Vários sistemas podem ser afetados. Em um estudo, foi evidenciado que o sistema mais afetado é o cardiovascular, o qual é a principal causa de morbidade e mortalidade, sendo a hipertensão arterial sistêmica (HAS) uma das comorbidades que mais frequentemente afetam pacientes com LES, juntamente com fibromialgia ${ }^{58,59,60}$.

Não é totalmente compreendida a existência do dano cardiovascular em pacientes com LES. O que tem sido motivo de estudo são mecanismos diferentes como as condições de inflamação de citocinas e triglicerídeos que conduzem a resistência à insulina como também ao dano endotelial. Em um estudo foi observado que pacientes com LES tem menos células progenitoras endoteliais, as quais tem função importante no reparo endotelial o que envolve em parte o desenvolvimento de aterosclerose ${ }^{58}$.

Vários marcadores séricos foram propostos como auxiliadores no diagnóstico de aterosclerose e complicações trombóticas. Entre vários desses a Proteína C-reativa (PCR) é a mais estudada. Há também marcadores de trombose como ativador de plasminogênio I (PAI-I) ou fibrinogênio. A PCR é produzida em resposta a IL-" 6 no fígado 48 .

O comprometimento renal é um importante indicador de morbidade e mortalidade no LES e acomete metade dos pacientes em algum período da doença. A NL é a manifestação visceral mais comum. Tem ampla clínica com aparecimento de deterioração progressiva dos rins, hematúria e proteinúria. Por 
REIS, Camila Carneiro dos; PEREIRA, Sâmia Emanuely da Silva; DE SOUZA, Luan Kelves Miranda.

1 conta disso, acompanhar a evolução do acometimento dos rins é de extrema importância, a qual entre os parâmetros para análise é válido citar a proteinúria na urina de 24 horas, creatinina sérica e sedimento urinário a fresco $55,64,65,66$.

Entre as diversas manifestações clínicas, a LES também pode apresentar entre elas sinais de alterações neuro cognitivas, com comprometimento frontosubcortical. No entanto, são poucas as evidências em estudos publicados sobre a relação entre o dano da doença sistêmica e a disfunção cognitiva ${ }^{67}$.

O tratamento de LES é complexo e depende das alterações laboratoriais e sinais e sintomas de cada paciente. $O$ tratamento tem a parte medicamentosa e não medicamentosa o que inclui uso de anti-inflamatórios não esteroidais, glicocorticoides, imunossupressores, como também orientações sobre prática de exercícios físicos, uso de protetor solar, dieta hipossódica e restrições para o uso de álcool e tabaco ${ }^{68}$.

Devido a essa diversidade e complexidade, vários pacientes não aderem de forma completa à terapia o que ocasiona em prejuízo para a qualidade de vida de muitos e alterações emocionais, como depressão, sendo necessário apoio social e abordagem interdisciplinar, pois podem causar agravamento da doença ${ }^{69,70}$.

É importante ressaltar que pacientes com LES são suscetíveis a adquirir outras infecções, como tuberculose pulmonar. Em estudos foram descritos pacientes adultos em uso de medicamentos imunossupressões com LES, o qual é um fator facilitador dessas infecções, particularmente glicocorticoides. Esses medicamentos, por não terem uma especificidade alta enfraquecem as defesas do corpo. Esse risco aumentado também se deve à diminuição de linfócitos $T$ $\mathrm{CD}^{+}$, neutropenia, déficit dos componentes do sistema complemento e linfopenia ${ }^{71,72}$.

Múltiplos autoanticorpos e hipergamaglobulinemia policlonal são produzidas nas LES contras antígenos nucleares. E essa é umas causas da inflamação grave devido o depósito desses autoanticorpos em vários órgãos, como pele, articulações e rins. Porém mesmo tendo hipergamaglobulinemia, esses pacientes são acometidos por infecções graves, como mencionado no parágrafo anterior ${ }^{60,61}$.

Segundo estudos, em relação ao prognóstico renal os piores fatores incluem hipertensão, trombocitopenia, creatininemia aumentada, baixa adesão 
REIS, Camila Carneiro dos; PEREIRA, Sâmia Emanuely da Silva; DE SOUZA, Luan Kelves Miranda.

1 terapêutica e diagnóstico tardia. As infecções, o tromboembolismo e o comprometimento cardiovascular são contribuintes importantes na mortalidade de pacientes com LES ${ }^{62}$. Porém a sobrevida e o prognóstico geral da doença aumentaram nas últimas décadas embora q qualidade de vida seja inferior à da população sem a doença devido a vários fatores já mencionados anteriormente ${ }^{63}$.

\section{CONCLUSÃO}

Como dito, o lúpus eritematoso sistêmico é uma doença autoimune, que provoca diversas repercussões psicológicas e físicas. Face a essa relevância, este artigo trouxe uma visão amadurecida sobre a importância de conhecer os principais mecanismos envolvidos na fisiopatologia do LES. Foi visto que os dados acerca das possíveis associações entre as citocinas citadas e o LES são evidentes, mostrando que alterações nesses componentes podem levar a maior atividade da doença.

A partir da pesquisa, constatou-se que as citocinas desempenham um papel importante na patogênese do LES. Pois, foi visto que a IL-4 atua na inflamação, além de regulação da atividade de células T; e a IL-6 está envolvida na produção de auto-anticorpos em pacientes com LES, e também considerada importante biomarcador de lúpus nefrítico (LN), juntamente com o TNF- $\alpha$, que tem sido alvo terapêutico em doenças imunomediadas e reumáticas. Além dessas, a IL-10 que mesmo sendo considerada uma citocina anti-inflamatória, está superexpressada em pacientes com lúpus. Por fim, a IL17 também foi considerada importante na patogênese do LES, no entanto, seu lugar exato dentro dos mecanismos que levam ao LES continua a ser definido. Dessa forma, as citocinas supracitadas desempenham um papel na patogênese da doença lúpica.

Dessa forma, devido a limitação de pequenas amostras e curta duração dos estudos realizados, mais estudos são necessário para avaliar não apenas 0 papel das citocinas envolvidas na fisiopatologia do LES, mas também o momento exato de sua participação e seus efeitos a longo prazo, a fim de facilitar o desenvolvimento de novos alvos terapêuticos, adequar as dosagens e as vias de administração, para assim, refinar o potencial terapêutico. 
REIS, Camila Carneiro dos; PEREIRA, Sâmia Emanuely da Silva; DE SOUZA, Luan Kelves Miranda.

\section{REFERÊNCIAS:}

1. $\mathrm{Xu} \mathrm{J}$ et al. White-matter volume reduction and the protective effect of immunosuppressive therapy in systemic lupus erythematosus patients with normal appearance by conventional magnetic resonance imaging. J. Rheumatol. 2019; (5):090967.

2. Chun HY et al. Cytokine IL- 6 and IL-10 as biomarkers in systemic lupus erythematosus. Journal of Clinical Immunology.2007; 27 (5):461-466.

3. Eriksson $\mathrm{C}$ et al. Autoantibody formation in patients with rheumatoid arthritis treated with anti-TNF $\alpha$. Ann. Rheum. Dis.2005;64 (3):403-407.

4. Doreau A et al. Interleukin 17 acts in synergy with B cell-activating factor to influence B cell biology and the pathophysiology of systemic lupus erythematosus. Nat. Immunol. 2009; 10 (7) p:778.

5. Shah $\mathrm{K}$ et al. Dysregulated balance of Th17 and Th1 cells in systemic lupusnerythematosus. Arthr. Res. Ther. 2010; 12 (2): R53.

6. Wong CK et al. Hyperproduction of IL-23 and IL-17 in patients with systemic lúpus erythematosus: implications for Th17-mediated inflammation in autoimmunity. Clin. Immunol.2008;127 (3):385-393.

7. Zhao XF et al. Increased serum interleukin 17 in patients with systemic lúpus erythematosus. Mol. Biol. Rep.2010; 37 (1):81-85.

8. Timóteo RP et al. Caracterização de marcadores inflamatórios associados a pacientes com lúpus eritematoso sistêmico em tratamento. Rev. Bras. Reumatol.2016; 56 (6):497- 503.

9. Hsieh SC, TSAI CY, YU CL. Potential serum and urine biomarkers in patients with lupus nephritis and the unsolved problems. Open access rheumatology: research and reviews.2016;8:81.

10. Ahsan $H$, Ali $A$, Ali R. Oxygen free radicals and systemic autoimmunity. Clinical \& Experimental Immunology. 2003;131 (3):398-404.

11. Dong $C$ et al. The role of interleukin - 4 in rheumatic diseases. Clin. Exp. Pharmacol. Physiol. 2018;45 (8):747-754.

12. Ouyang BS et al. Effects of electroacupuncture and simple acupuncture on changes of IL-1, IL-4, IL-6 and IL-10 in peripheral blood and joint fluid in patients with rheumatoid arthritis. Zhongguo. Zhen. Jiu. 2010;30 (10): 840844.

13. Ursaciuc $\mathrm{C}$ et al. Regulatory $\mathrm{T}$ cells and $\mathrm{TH} 1 / \mathrm{TH} 2$ cytokines as immunodiagnosis keys in systemic autoimmune diseases. Roum. Arch. Microbiol. Immunol. 2010; 69 (2): 79-84. 
REIS, Camila Carneiro dos; PEREIRA, Sâmia Emanuely da Silva; DE SOUZA, Luan Kelves Miranda.

14. Jantova S, Cipak L, Letasiova S. Berberine induces apoptosis through a mitochondrial/caspase pathway in human promonocytic U937 cells. Toxicol. In. Vitro. 2007; 21 (1): 25-31.

15. Nelms $\mathrm{K}$ et al. The IL-4 receptor: signaling mechanisms and biologic functions. Annual. Rev Immunol. 1999;17 (1): 701-738.

16. Guimarães PM et al. Cytokines in systemic lupus erythematosus: far beyond Th1/Th2 dualism lupus: cytokine profiles. Immunol. Cell. Biol. 2017; 95 (9):824-831.

17. Tshilela KA et al. Glomerular cytokine expression in murine lupus nephritis. Clin. Exp. Nephr. 2016; 20 (1): 23-29.

18. Dolff $S$ et al. Disturbed Th1, Th2, Th17 and Treg balance in patients with systemic lupus erythematosus. Clin. Immunol. 2011; 141 (2): 197-204.

19. Comte D et al. Brief Report: CD4+ T Cells From Patients With Systemic Lupus Erythematosus Respond Poorly to Exogenous Interleukin - 2. Arthritis. Rheum. 2017; 69 (4): 808-813.

20. Ding HJ, Gordon C. New biologic therapy for systemic lupus erythematosus. Curr. Opin. Pharmacol.2013; 13 (3): 405-412.

21. Ekdahl KN et al. Cardiovascular disease in haemodialysis: role of the intravascular innate immune system. Nat. Ver. Nephrol.2017;13 (5): 285.

22. Hassanian SM, Avan A, Ardeshirylajimi A. Inorganic polyphosphate: a key modulator of inflammation. J. Thromb. Haemost.2017; 15 (2): 213-218.

23. Niyonzima $\mathrm{N}$ et al. Complement activation by cholesterol crystals triggers a subsequente cytokine response. Mol. Immunol. 2017; 84: 43-50.

24. Witkowski M, Landmesser, Ulf, Rauch, Ursula. Tissue factor as a link between inflammation and coagulation. Trends in Cardiovascular Medicine. 2016; 26 (4): 297-303.

25. Gordon SM, Remaley AT. High density lipoproteins are modulators of protease activity: Implications in inflammation, complement activation, and atherothrombosis. Atherosclerosis. 2017; 259: 104-113.

26. Majai $G$ et al. Decreased apopto-phagocytic gene expression in the macrophages of systemic lupus erythematosus patients. Lupus. 2014; 23 (2): 133-145.

27. Clark DN et al. Cytokine inhibition as a strategy for treating systemic lúpus erythematosus. Clin. Immunol, 2013; 148 (3): 335-343. 
REIS, Camila Carneiro dos; PEREIRA, Sâmia Emanuely da Silva; DE SOUZA, Luan Kelves Miranda.

28. Peng $\mathrm{H}$ et al. Role of interleukin-10 and interleukin-10 receptor in systemic lúpus erythematosus. Clin. Rheumatol. 2013; 32 (9): 1255-1266.

29. Fiorentino DF, Bond MW.; Mosmann, T. R. Two types of mouse T helper cell. IV. Th2 clones secrete a factor that inhibits cytokine production by Th1 clones. J Exp Med. 1989; 170 (6): 2081-2095.

30. Moore KW et al. Homology of cytokine synthesis inhibitory factor (IL-10) to the Epstein- Barr virus gene BCRFI. Science. 1990; 248 (4960): 1230-1234.

31. O'garra A, Vieira P. TH 1 cells control themselves by producing interleukin10. Nat. Rev. Immunol. 2007; 7 (6): 425.

32. Fillatreau S, Gray D, Anderton SM. Not always the bad guys: B cells as regulators of autoimmune pathology. Nat Rev Immunol, 2008; 8 (5): 39.

33. Ryan JJ et al. Mast cell homeostasis: a fundamental aspect of allergic disease. Crit. Rev. Immunol. 2007; 27 (1).

34. Williams LM et al. Interleukin-10 suppression of myeloid cell activation-a continuing puzzle. Immunology. 2004; 113 (3): 281-292.

35. Sun $Z$ et al. Serum IL-10 from systemic lupus erythematosus patients suppresses the differentiation and function of monocyte-derived dendritic cells. J. Biomed. Res. 2012; 26 (6): 456-466.

36. Tian $\mathrm{G}$ et al. Targeting IL-10 in auto-immune diseases. Cell. Biochem. Bioph, 2014; 70 (1): 37-49.

37. Commins S, Steinke JW, Borish L. the extended II-10 superfamily: il-10, II-19, II-20, II-22, II-24, II-26, II-28, and II-29. J. Allergy. Clin. Immunol. 2008; 121 (5): $1108-1111$.

38. Jankovic $D$ et al. Conventional T-bet+ Foxp3- Th1 cells are the major source of hostprotective regulatory IL-10 during intracellular protozoan infection. J. Exp. Med. 2007; 204 (2): 273-283.

39. Mosser DM.; ZHANG, X. Interleukin - 10: new perspectives on an old cytokine. Immunol. Rev. 2008; 226 (1): 205-218.

40. Pereira VM et al. Infliximab-Induced Lupus: A Case Report. GE-Port. J. Gastroenterol. 2017; 24 (2): 84-88.

41. Warren R et. Al, Níveis de IL-17A no lúpus eritematoso sistêmico associados a marcadores inflamatórios e menores taxas de malignidade e dano cardíaco: Evidência para um duplo papel. Eur J Rheumatol.2017; 4 (1): 29-35.

42. Rabelo LBC, Silva JMA, Lima ME. A. Trabalho e adoecimento psicossomático: reflexões sobre o problema do nexo causal. Psicol: Ciência.Profissão, 2018; 38 (1): 116-128. 
REIS, Camila Carneiro dos; PEREIRA, Sâmia Emanuely da Silva; DE SOUZA, Luan Kelves Miranda.

43. Ballone J, Orolani I. Da emoção à lesão: um guia de medicina psicossomática. Da emoção à lesão: um guia de medicina psicossomática. Manole, 2007.

44. Valencia-pacheco $\mathrm{G}$ et al. Serological and molecular analysis of parvovirus B19 infection in Mayan women with systemic lupus erythematosus in Mexico. Colom. Med. 2017; 48 (3): 105-112.

45. Encalada-garcía C. Células dendríticas e interferones en el lupus eritematoso sistémico. Rev.Colomb.Reumatol. 2017; 24 (3): 177-184.

46. Sousa JR et al. Effect of vitamin D supplementation on patients with systemic lúpus erythematosus: a systematic review. Rev. Bras. Reumatol.2017 Oct; 57 (5): 466-471.

47. Simioni J, Heimovski F, Skare T. On lupus, vitamin D and leukopenia. Rev. Bras. Reumatol. 2016; 56 (3): 206-211.

48. Hernández MY, Guibert TZM, Reyes LGA. Correlación de las cifras de proteína $C$ reactiva y aterosclerosis en pacientes con lúpus eritematoso sistémico. Rev. Cub. Reumatol. 2015; 17(2): 126-131.

49. Singh RR et al. Differential contribution of IL-4 and STAT6 vs STAT4 to the development of lupus nephritis. J. Immunol. 2003; 170 (9): 4818-4825.

50. Yung S, Chan TM. Mechanisms of kidney injury in lupus nephritis-the role of anti-dsDNA antibodies. Front in immunol. 2015; 6: 475.

51. Kokuina E et al. Anticuerpos antinucleares específicos y afectaciones orgánicas en 180 pacientes con lupus eritematoso sistémico. Rev. Cub. Reumatol. 2015; 17 (2): 104-111.

52. Canto LM et al. Association of PDCD1 polymorphism to systemic lupus erythematosus and rheumatoid arthritis susceptibility. Rev. Bras. Reumatol. 2016; 56 (6): 483-489.

53. Herrera AP et al. ANCA-Positive pauci-immune crescentic glomerulonephritis in a patient with systemic lupus erythematosus. J. Bras. Nefrol. 2017; 39 (4): 454-457.

54. Dias $\mathrm{CB}$ et al. Clinical and histological features of patients with membranoproliferative glomerulonephritis classified by immunofluorescence findings. J. Bras. Nefrol. 2017; 39 (4): 447-453.

55. Laguarde $\mathrm{M}$ et al. Cocientes urinarios Proteína-Creatinina y AlbúminaCreatinina em pacientes con lupus eritematoso sistémico. Acta. Bioquí. Clín. Latinoame. 2016; 50 (1): 5- 10.

56. Oliveira VM et al. Serum markers thrombophilia in pregnant women with Systemic Lupus Erythematosus. Rev Bras. Saúde. Mat Infan. 2017; 17 (4): 833-842. 
REIS, Camila Carneiro dos; PEREIRA, Sâmia Emanuely da Silva; DE SOUZA, Luan Kelves Miranda.

57. Sakamoto AP et al. Initial digital vasculitis in a large multicenter cohort of childhoodonset systemic lupus erythematosus. Rev. Bras. Reumatol. 2017; 57 (6): 583-589.

58. Batun-Garrido JAJ, Radillo-Alba HÁ, Hernandez NE. Riesgocardiovascular en lupus eritematoso sistémico.Rev.Colomb.Reumatol. 2016; 23 (4): 242- 249.

59. Ramírez CF et al. Caracterización clínica paraclínica y epidemiológica de los pacientes con Lupus Eritematoso Sistémico del Hospital Universitario Hernando Moncaleano Perdomo de Neiva. Rev. Med. Risaralda.2017; 23 (2): 23-28.

60. Navarro $\mathrm{M}$ et al. Leptina y factores de riesgo cardiovascular en pacientes con Lupus Eritematoso sistémico. Comum. Salud, 2017; 13 (2): 3-9.

61. Errante PR et al. Associação de imunodeficiência primária com lúpus eritematoso sistêmico: revisão da literatura e as lições aprendidas pela Divisão de Reumatologia de um hospital universitário terciário em São Paulo. Rev. Bras. Reumatol. 56 (1): 58-68.

62. Aguirre $\mathrm{V}$ et al. Recomendaciones sobre el manejo del compromiso renal del lúpus eritematoso sistémico: Documento de Consenso de las Sociedades Chilenas de Nefrología y Reumatología. Rev. méd. Chile, Santiago. 2015; 143 (12): 1569-1578.

63. Díaz-cerezo $S$ et al. Análisis coste-efectividad de Belimumab en pacientes con lúpus eritematoso sistémico en España. Farm. Hosp. 2015; 39 (3): 161-170.

64. Silva JP, Amadei JL. Influence of medical care in the quality of life (WHOQOL100 ) of women living with systemic lupus erythematosus. Rev. bras de Reumatol. 2016; 56 (3): 198-205.

65. Restrepo EM et al. Study of the agreement between clinical opinion of rheumatologists regarding the need for immunosuppression and the result of renal biopsy in adult patients with lupus nephritis. Rev. Colom. Reumatol. 2016; 23 (2): 73-78.

66. González-Sánchez DA et al. Papel de la vía de señalización del TWEAK/Fn14 en la nefritis lúpica y otros escenarios clínicos. Nefrología.(Madrid). 2017; 37 (2): 118-125.

67. Dorman $\mathrm{G}$ et al. Disfunción cognitiva en lupus eritematoso sistémico y su asociación com actividad y daño. Medicina. (B. Aires). 2017; 77 (4): 257-260.

68. Neder PRB, Ferreira EAP, Carneiro JR. Adesão ao tratamento do lúpus: efeitos de três condições de intervenção. Psicol. Saúde. Doenças.2017; 18 (1): 203-220.

69. Alves VLP et al. Significados do adoecer para pacientes com lúpus eritematoso sistêmico: revisão da literatura. Rev. Bras. Reumatol. 2015; 55 (6): 522-527. 
REIS, Camila Carneiro dos; PEREIRA, Sâmia Emanuely da Silva; DE SOUZA, Luan Kelves Miranda.

70. Martinez M et al. Tratamiento psicológico en pacientes lupus eritematoso sistémico: Uma revisión sistemática. Ter. Psicol. Santiago. 2016; 34 (3): 167181.

71. Freire EAM, Souto LM, Ciconelli RM . Medidas de avaliação em lúpus eritematoso sistêmico. Rev Bras Reumatol. 2011; 51 (1): 70-80.

72. Skare TL et al. Infections and systemic lupus erythematosus. Einstein. 2016; 14 (1): 47-51. 
REIS, Camila Carneiro dos; PEREIRA, Sâmia Emanuely da Silva; DE SOUZA, Luan Kelves Miranda.

\begin{tabular}{|c|c|c|c|}
\hline & PUBMED & BIRENE & SCIELO \\
\hline Palavras-chave & $\begin{array}{c}\text { - Systemic lúpus } \\
\text { erythematosus } \\
\text { - Cytokines } \\
\text { - Autoimune disease } \\
\text { - Inflammation } \\
\text { *conectivos: and }\end{array}$ & $\begin{array}{c}\text { - Systemic lupus } \\
\text { erythematosus } \\
\text { and } \\
\text { - Cytokines } \\
\text { and } \\
\text { - Autoimune disease }\end{array}$ & $\begin{array}{c}\text { - Systemic lupus } \\
\text { erythematosus } \\
\text { or } \\
\text { - Cytokines } \\
\text { and } \\
\text { - Autoimune disease }\end{array}$ \\
\hline Filtros & $\begin{array}{c}10 \text { anos } \\
(2009-2019)\end{array}$ & \multicolumn{2}{|c|}{$2005-2019$} \\
\hline Artigos encontrados & 732 & 500 & 8 \\
\hline Artigos selecionados & 57 & 20 & 3 \\
\hline $\begin{array}{c}\text { Total de } \\
\text { Selecionados }\end{array}$ & \multicolumn{3}{|c|}{80} \\
\hline
\end{tabular}




\begin{tabular}{|c|c|c|c|}
\hline Autor & Título & $\begin{array}{l}\text { Tipo de } \\
\text { Estudo }\end{array}$ & Ano \\
\hline $\begin{array}{l}\text { - Hye-Young Chun } \\
\text { - Jae-Wook Chung } \\
\text { - Hyoun-Ah Kim } \\
\text { - Jeong-Moon Yun } \\
\text { - Ja-Young Jeon } \\
\text { - Young-Min Ye } \\
\text { - Seung-Hyun Kim } \\
\text { - Hae-Sim Park } \\
\text { - Chang-Hee Suh }\end{array}$ & $\begin{array}{l}\text { Citocina IL-6 e IL-10 } \\
\text { como biomarcadores no } \\
\text { lúpus eritematoso } \\
\text { sistêmico }\end{array}$ & Experimental & 2007 \\
\hline $\begin{array}{l}\text { - Susan Yung } \\
\text { - Tak Mao Chan }\end{array}$ & $\begin{array}{l}\text { Mecanismos de Lesão } \\
\text { Renal na Nefrite Lúpica - } \\
\text { o Papel dos Anticorpos } \\
\text { Anti-dsDNA }\end{array}$ & Experimental & $2015^{11}$ \\
\hline $\begin{array}{l}\text { - Cristiane Bitencourt Dias } \\
\text { - Leonardo Testagrossa } \\
\text { - Lectícia Jorge } \\
\text { - Denise Malheiros } \\
\text { - Viktoria Woronik }\end{array}$ & $\begin{array}{l}\text { Características clínicas e } \\
\text { histológicas de pacientes } \\
\text { com glomerulonefrite } \\
\text { membranoproliferativa } \\
\text { classificados por achados } \\
\text { de imunofluorescência }\end{array}$ & Revisão & 2017 \\
\hline $\begin{array}{l}\text { - Vitalina de Souza } \\
\text { Barbos } \\
\text { - Jozelia Rêgo } \\
\text { - Nílzio Antônio da Silva }\end{array}$ & $\begin{array}{l}\text { Possível papel das } \\
\text { adipocinas no lúpus } \\
\text { eritematoso sistêmico e } \\
\text { na artrite reumatoide }\end{array}$ & Revisão & $\begin{array}{r}18 \\
2012 \\
19 \\
20\end{array}$ \\
\hline - Carlos Encalada García & $\begin{array}{l}\text { Células dendríticas e } \\
\text { interferones en el lupus } \\
\text { eritematoso sistémico }\end{array}$ & Revisão & 2017 \\
\hline $\begin{array}{l}\text { - Warren Raymond } \\
\text { - Gro Ostli-Eilertsen } \\
\text { - Sheynae Griffiths } \\
\text { - Johannes Nossent }\end{array}$ & $\begin{array}{l}\text { Níveis de IL-17A no lúpus } \\
\text { eritematoso sistêmico } \\
\text { associados a marcadores } \\
\text { inflamatórios e menores } \\
\text { taxas de malignidade e } \\
\text { dano cardíaco: Evidência } \\
\text { para um duplo papel }\end{array}$ & Transversal & $\begin{array}{r}23 \\
24 \\
2017_{25} \\
26\end{array}$ \\
\hline $\begin{array}{l}\text { - Song-Chou Hsieh } \\
\text { - Chang-Youh Tsai } \\
\text { - Chia-Li Yu }\end{array}$ & $\begin{array}{l}\text { Potenciais biomarcadores } \\
\text { de soro e urina em } \\
\text { pacientes com nefrite } \\
\text { lúpica e problemas não } \\
\text { resolvidos }\end{array}$ & Revisão & 2016 \\
\hline
\end{tabular}

31 Tabela 02: Alguns dos artigos selecionados a partir das buscas nas bases de dados. 